\title{
Factors Associated with the Unsuppressed Viral Load of Children on Antiretroviral Therapy Followed Up in the Gbêkê Region (Côte d'Ivoire)
}

\author{
Tanoh-Aka Aude Hélène*, Siallou-Avi Christelle, Yao Kouassi Christian, Adou Leïoh Roméo, \\ Yeboua Kossonou Roland, Sahi Landryse, Amani Alexise, Tuo Wako Tianwa Alice, \\ Gawa Kokora Junior, Asse Kouadio Vincent
}

University Hospital of Bouaké, Bouaké, Côte d'Ivoire

Email: ^audeaka@gmail.com, avichristelle611@gmail.com, yaokc777@gmail.com, leioh91@hotmail.fr, rolandyeboua13@gmail.com, firstsahi@yahoo.com, amanialexise91@gmail.com, tuoalice1@gmail.com, kokorajunior@gmail.com, assevinc2014@gmail.com

How to cite this paper: Hélène, T.-A.A., Christelle, S.-A., Christian, Y.K., Roméo, A.L., Roland, Y.K., Landryse, S., Alexise, A., Alice, T.W.T., Junior, G.K. and Vincent, A.K. (2021) Factors Associated with the Unsuppressed Viral Load of Children on Antiretroviral Therapy Followed Up in the Gbêkê Region (Côte d'Ivoire). Open Journal of Pediatrics, 11, 723-737. https://doi.org/10.4236/ojped.2021.114067

Received: October 29, 2021

Accepted: December 5, 2021

Published: December 8, 2021

Copyright $\odot 2021$ by author(s) and Scientific Research Publishing Inc. This work is licensed under the Creative Commons Attribution International License (CC BY 4.0).

http://creativecommons.org/licenses/by/4.0/

\section{(c) (i) Open Access}

\begin{abstract}
Introduction: Unsuppressed viral load (VL) in immunocompromised children on antiretroviral therapy (ART) increases the risk of child morbidity and death. The aim of the study was to identify factors associated with unsuppressed viral load in children on ART for the improvement of prognosis. Patients and Methods: this is a retrospective, descriptive and analytical study carried out from July 2015 to December 2019 in the 28 pediatric HIV/AIDS treatment centers supervised by the NGO IRAA in the region of Gbêkê. It Included children from 0 to 15 years who were HIV positive, on ART for at least 6 months with at least one viral load. The variables studied were socio-demographic, diagnostic and evolutionary. Data analysis was descriptive and analytical with a significance level of $\mathrm{p}<0.05$. Results: out of 329 children included, 118 (62 boys, 53 girls) had a non-suppressed VL, i.e. a prevalence of $36 \%$. The mean age at diagnosis was 61 months. The mother was a small trader (36.4\%), illiterate (45.8\%). Unsuppressed viral load was significantly associated with poor nutritional status at the start of treatment $(\mathrm{p}<$ $0.001)$, non-compliance with treatment $(\mathrm{p}<0.001)$, poor maternal education $(p=0.011)$ and the lack of follow-up of the mother in the context of PMTCT $(\mathrm{p}=0.03)$. Conclusion: Unsuppressed viral load is common in children on ART in the Gbêkê region. It mainly concerns the child who did not comply with ART, and whose mother was not followed within the framework of PMTCT. Strengthening early detection, early initiation of ART, PMTCT and increased therapeutic education strategies would improve the prognosis of children infected with HIV.
\end{abstract}




\section{Keywords}

Child, HIV, Unsuppressed Viral Load, Compliance, Associated Factors, Côte d'Ivoire

\section{Introduction}

Despite scientific advances and advances in the fight against HIV/AIDS infection over the past decade, HIV/AIDS infection continues to be a major public health problem around the world. In 2020, 38 million people were living with HIV, including 1.8 million children under the age of 15 [1]. For the management of pediatric cases, new classes of antiretrovirals with dosage forms suitable for children have been developed. This allows us to hope for the control of this pandemic. But access to ART is a problem because only $53 \%$ of infected children have access to this therapy [1]. For children on ART, viral load monitoring is the recommended approach to verify the effectiveness of treatment and to determine whether viral load suppression is achieved and maintained [2]. According to UNAIDS, in 2019 globally, 59\% of people living with HIV had a suppressed viral load [1]. In the study by Cissé et al. [3] in Senegal in 2015, 64\% of the children in the cohort had treatment failure. This proportion was $17.6 \%$ in the study by Penda et al. [4]. In Benin, Zohoun et al. [5] reported in 2019, a prevalence of treatment failure of $24.4 \%$ with as associated factors, poor compliance, the occurrence of comorbidities such as tuberculosis, complex treatment regimens and molecule substitutions more than twice in the same therapeutic line. In the case of Côte d'Ivoire, the prevalence of HIV infection reported in 2018 was $2.6 \%$, or 460,000 people living with HIV. Among its people living with HIV, there were 31,000 children under the age of 15 , of whom 12,349 were on ART [6]. For these children on ART, the prevalence of treatment failure is not precisely known nationally. However in the Gbêkê region, Asse et al. [7] reported in 2019 in the pediatric department of the University Hospital of Bouake that $38.3 \%$ of children followed in the context of PMTCT had an unsuppressed viral load, but without specifying the significant factors associated with this condition. The aim of the study was to determine the prevalence and factors associated with unsuppressed viral load for the improvement of prognosis in children infected with HIV.

\section{Methods}

This was a retrospective descriptive and analytical study carried out from July $1^{\text {st }}$, 2015 to December 2019 in the Gbêkê health region comprising five health districts: South Bouaké, North-East Bouaké, North-West Bouaké, Béoumi, Sakassou. This health region covered 1410 localities spread over an area of approximately $8996 \mathrm{~km}^{2}$ (2.79\% of the Ivorian national territory). It has 1,082,958 inhabitants [8]. In 2019, the Gbêkê health region included 116 first-contact health fa- 
cilities, 02 General Hospitals, 01 University Hospital (Figure 1) [8]. In this Gbêkê health region, pediatric HIV care activities are supported and supervised by the Non-Governmental Organization Institute for Research and Action in Africa (IRAA) in 28 health facilities. The study took place in these 28 pediatric HIV infection management centers. The study population consisted of all children aged 0 to 15 years living with HIV diagnosed on clinical and laboratory

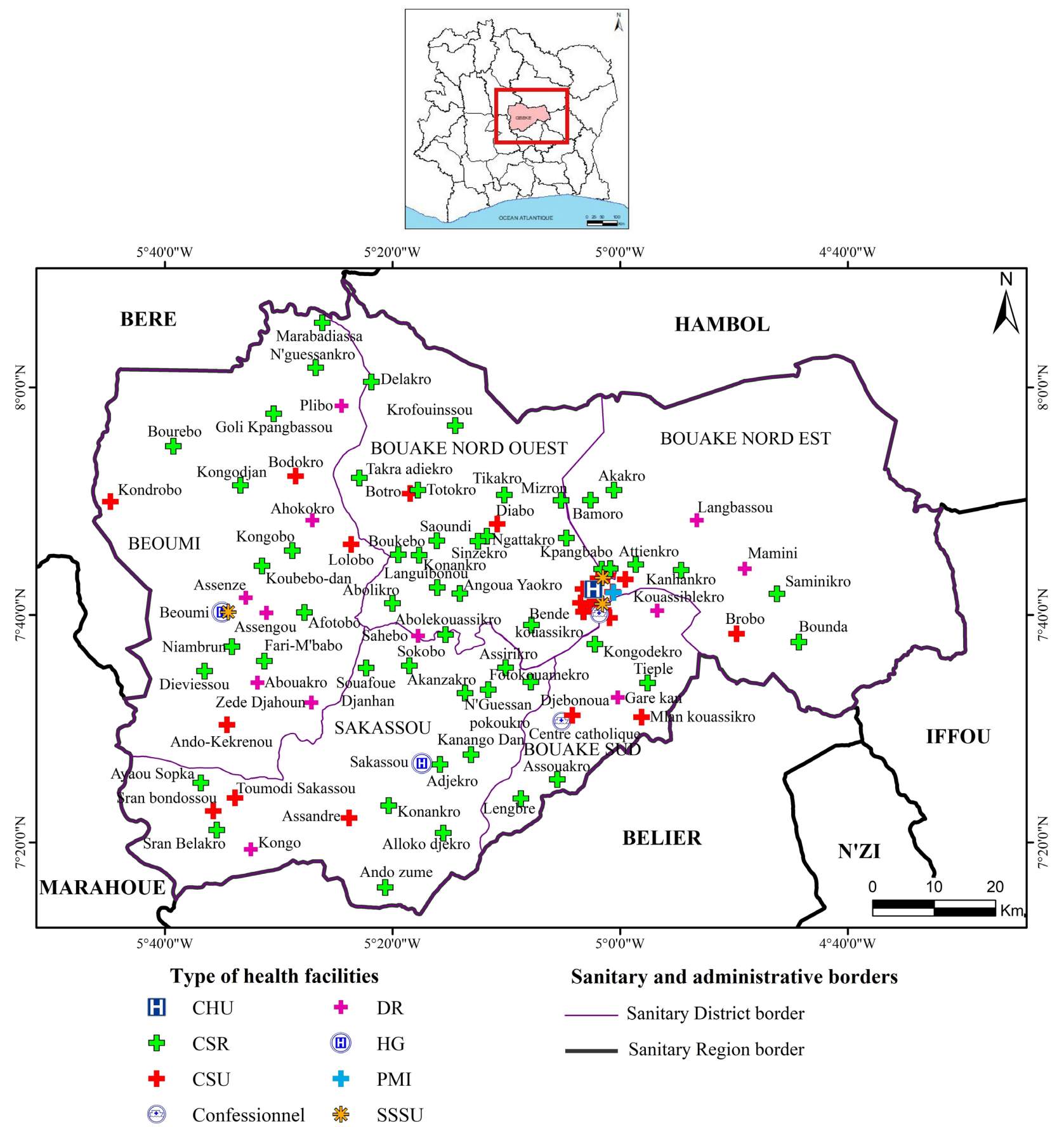

Source: Direction regionale santé Gbêkê, 2018; DPPEIS, 2017

Author : SREU Eric, 2018

Figure 1. Location and presentation of the Gbêkê health region [8]. 
grounds, treated and followed up at one of the treatment sites. All HIV positive children aged 0 to 15 years, on ARV treatment for at least 6 months and having achieved a viral load in the $6^{\text {th }}$ month were included in the study. All HIV positive children aged 0 to 15 years on treatment for less than 6 months, or having more than 6 months of treatment but not having received a viral load measurement were not included until after 12 months of treatment. The sample consisted of all children infected with HIV, registered and followed up in the various HIV AIDS testing and care centers in the Gbêkê regions. These received technical and financial support from IRAA and met the inclusion and non-inclusion criteria. The data was collected over a period of 4 months from January to April 2020. After agreement of the various officials involved in the study, one to three field visits to each site for the care of HIV infection was carried out. Once on the site, the database of all children in care was queried. From this database, all the children meeting the inclusion criteria were selected from the customer code. Data were collected from the individual patient file of the selected children. In the client file, we studied the following variables: 1) the socio-demographic characteristics of the child (sex, age, level of education, place of residence) and of the parents (index, level of education, HIV serology, initiation of antiretroviral treatment, the outcome), 2) the child's HIV parameters at diagnosis (Prevention of Mother-to-Child Transmission in the mother, age at diagnosis, place and date of diagnosis, cotrimoxazole prophylaxis, opportunistic infections, type of HIV, CDC clinical stage, CD4 count, viral load, place of care, date of initiation of treatment and ART regimen, weight and height), 3) evolution at visits of M3, M6, M12 (CD4 count, viral load, compliance education, CDC clinical stage, weight, height, opportunistic infections, cotrimoxazole prophylaxis, compliance and outcome). The study was carried out after obtaining authorization from the General Directorate, the Medical and Scientific Directorate and the Head of the Pediatric Department of the Bouaké University Hospital, the Regional Directorate as well as the Departmental Directorates of the Gbêkê region. Anonymity and confidentiality were respected by assigning an anonymity number to each survey sheet. Data were entered from Epi info 7 computers software. The analysis was descriptive and analytical. To investigate factors associated with unsuppressed viral load, we used the Odd ratio with a $95 \%$ confidence interval and a significant $\mathrm{p}$-value $<0.05$.

\section{Results}

\section{- Sociodemographic characteristics of children and mothers}

Out of 329 children under the age of 15 included, 118 had an unsuppressed viral load, ie a prevalence of $36 \%$. The child whose viral load was not suppressed was a boy in 62 cases and a girl in 53 cases, for a sex ratio of 1.2. At the time of diagnosis, the child's age was 60 months or less in $60.7 \%$ of cases with an average age of 61 months (extremes 2 and 168 months). The age at the start of treatment was greater than or equal to 60 months in $47.9 \%$ OF cases and greater than or equal to 24 months in $66.7 \%$ of cases with a mean age of 65.8 months (extremes: 
2 and 168 months). The child was out-of-school in 57.6\% of cases, and in primary school in $34.8 \%$ when he was in school. The mother of the child was illiterate $45.8 \%$ of the time. Her activity was small trading in $36.4 \%$ of cases. She was HIV positive in $83 \%$ of cases and alive in $72 \%$. Concerning the socio-demographic aspects, there was no significant difference between the two groups of children (suppressed viremia and non-suppressed viremia) for sex, age at diagnosis, age at initiation of treatment, mother's education, mother's occupation, mother's serology and mother's outcome (Table 1 ). However, a significant difference between the two groups was noted for the educational level of the child $(p<0.001)$ and place of residence $(\mathrm{p}=0.02)$ (Table 1$)$.

\section{- Diagnostic characteristics}

The mother was followed up for PMTCT in 15\% of cases. In children with unsuppressed viremia, serotype HIV 1 was found in $100 \%$ of cases at diagnosis. At the clinical level, the child was in Stage A of the CDC classification or asymptomatic in $60.2 \%$ of cases. He had a CD 4 count $>500$ in $60 \%$ of cases, with an average of $679 \pm 487$ CD4 (extremes: 1 and 1834 CD4). The child was in good nutritional status in $24.6 \%$ (Table 2). The main pathologies associated with HIV infection in children with unsuppressed viremia were malnutrition (55.7\%), tuberculosis (11.5\%), pneumonia (6.55\%) and rhinobronchitis (6.55\%) (Table 2). For the diagnostic aspects, there was no significant difference between the two groups of children concerning the CD4 count at the initiation of the treatment. A statistical difference was observed for the nutritional status of the child ( $\mathrm{p}<$ $0.001)$, the mother's follow up for PMTCT $(<0.001)$ and for the associated pathologies $(\mathrm{p}=0.001)$ (Table 2).

\section{- Therapeutic and evolutionary characteristics}

The main treatment regimens prescribed combined two nucleoside reverse transcriptase inhibitors (NRTIs) and a non-nucleoside reverse transcriptase inhibitor (NNRTI) in $71.7 \%$ of cases and two nucleoside reverse transcriptase inhibitors (NRTIs) and an inhibitor of protease (PI) boosted in $26.5 \%$ of cases (Table 3). ART compliance was achieved in 55.7\% of cases. Cotrimoxazole prophylaxis was initiated in $69 \%$ of cases. The main reasons for non-compliance identified were forgetting (30\%), non-compliance with prescriptions (25\%) and treatment interruption (15\%). The child was still in the active queue $(94.8 \%$; $112 / 118)$, transferred to another care center $(2.5 \% ; 3 / 118)$, lost to follow-up $(1.7 \% ; 2 / 118)$ and deceased $(0.9 \% ; 1 / 118)$. With regard to treatment characteristics, there was no statistically significant difference between the two groups of children in terms of cotrimoxazole treatment. A statistical difference was observed for treatment regimen $(p=0.018)$ and adherence to antiretroviral treatment $(\mathrm{p}<0.0001)($ Table 3$)$

\section{Factors associated with unsuppressed viraemia}

Factors associated with unsuppressed viral load were maternal education level $(\mathrm{p}=0.01$; odds ratio $=2.2)$, PMTCT follow-up $(\mathrm{p}=0.03)$, Nutritional status at the start of treatment $(\mathrm{p}<0.001)$, and compliance to ART $(\mathrm{p}<0.001$; odds ratio =9.8) (Table 4). 
Table 1. Sociodemographic characteristics of children living with HIV with viremia suppressed versus viremia not suppressed and their mothers.

\begin{tabular}{|c|c|c|c|c|c|}
\hline \multirow[b]{2}{*}{ Variables } & \multicolumn{2}{|c|}{ unsuppressed viremia } & \multicolumn{2}{|c|}{ suppressed viremia } & \multirow[b]{2}{*}{ p Value } \\
\hline & $\begin{array}{l}\text { Frequencies } \\
\qquad(\mathrm{n} / \mathrm{N})\end{array}$ & Percentage & $\begin{array}{l}\text { Frequencies } \\
\qquad(\mathrm{n} / \mathrm{N})\end{array}$ & Percentage & \\
\hline \multicolumn{6}{|l|}{ Sex } \\
\hline - Boy & $62 / 118$ & 52 & $95 / 211$ & 45 & 0.31 \\
\hline - Girl & $53 / 118$ & 45 & $112 / 211$ & 53 & \\
\hline - Unspecified & $3 / 118$ & 3 & $4 / 211$ & 2 & \\
\hline \multicolumn{6}{|c|}{ Age at diagnosis (month) } \\
\hline - $[0-24]$ & $43 / 118$ & 36.8 & $48 / 211$ & 22.7 & 0.07 \\
\hline - $[24-60]$ & $28 / 118$ & 23.9 & $63 / 211$ & 29.8 & \\
\hline - $[60-120]$ & $31 / 118$ & 26.5 & $69 / 211$ & 32.7 & \\
\hline - $[120-180]$ & $15 / 118$ & 12.8 & $28 / 211$ & 13.3 & \\
\hline \multicolumn{6}{|c|}{ Age at start of treatment (month) } \\
\hline - $[0-60]$ & $61 / 118$ & 52.1 & $91 / 211$ & 43.1 & 0.22 \\
\hline - $[60-180]$ & $56 / 118$ & 47.9 & $111 / 211$ & 52.6 & \\
\hline \multicolumn{6}{|l|}{ Child education level } \\
\hline - Out-of-school & $68 / 118$ & 57.6 & $57 / 211$ & 27.1 & $<0.001$ \\
\hline - Primary & $41 / 118$ & 34.8 & $98 / 211$ & 46.4 & \\
\hline - Secondary & $4 / 118$ & 3.4 & $7 / 211$ & 3.3 & \\
\hline - Unspecified & $5 / 118$ & 4.2 & $49 / 211$ & 23.2 & \\
\hline \multicolumn{6}{|l|}{ Residency } \\
\hline - Bouaké & $70 / 118$ & 59 & $125 / 211$ & 59.2 & 0.02 \\
\hline - Out of Bouaké & $29 / 118$ & 25 & $30 / 211$ & 14.2 & \\
\hline - Unspecified & $19 / 118$ & 16 & $56 / 211$ & 26.5 & \\
\hline \multicolumn{6}{|c|}{ Mother's level of education } \\
\hline - Illetrate & $54 / 118$ & 45.8 & $75 / 211$ & 35.5 & 0.06 \\
\hline - Primary & $8 / 118$ & 6.8 & $33 / 211$ & 15.6 & \\
\hline - Secondary & $12 / 118$ & 10.1 & $23 / 211$ & 10.9 & \\
\hline - Higher education & $0 / 118$ & 0 & $4 / 211$ & 2 & \\
\hline - Unspecified & $44 / 118$ & 37.3 & $76 / 211$ & 36 & \\
\hline \multicolumn{6}{|l|}{ Mother activity } \\
\hline - Small trader & $43 / 118$ & 36.4 & $69 / 211$ & 33 & 0.25 \\
\hline - Housewife & $37 / 118$ & 31.4 & $76 / 211$ & 36 & \\
\hline - Grower & $2 / 118$ & 1.7 & $0 / 211$ & 0 & \\
\hline - Others ${ }^{* *}$ & $3 / 118$ & 2.5 & $4 / 211$ & 2 & \\
\hline
\end{tabular}




\section{Continued}

\begin{tabular}{|c|c|c|c|c|c|}
\hline \multicolumn{6}{|l|}{ Mother serology } \\
\hline - HIV 1 Positive & $98 / 118$ & 83 & $162 / 211$ & 77 & 0.25 \\
\hline - Negative & $2 / 118$ & 15 & $2 / 211$ & 1 & \\
\hline - Unknown & $18 / 118$ & 2 & $47 / 211$ & 22 & \\
\hline \multicolumn{6}{|l|}{ Mother's outcome } \\
\hline - Alive & $85 / 118$ & 72 & $137 / 211$ & 65 & 0.42 \\
\hline - Dead & $24 / 118$ & 20 & $55 / 211$ & 26 & \\
\hline - Unknown & $9 / 118$ & 8 & $19 / 211$ & 9 & \\
\hline
\end{tabular}

${ }^{\star}$ Child living with HIV; ${ }^{* \star}$ Caregiver (1), teacher (1), warden (1).

Table 2. Diagnostic characteristics of $\mathrm{HALE}^{\star}$ without suppressed viraemia.

\begin{tabular}{|c|c|c|c|c|c|}
\hline \multirow[b]{2}{*}{ Variables } & \multicolumn{2}{|c|}{ unsuppressed viremia } & \multicolumn{2}{|c|}{ suppressed viremia } & \multirow[b]{2}{*}{ pValue } \\
\hline & $\begin{array}{c}\text { Frequencies } \\
(\mathrm{n} / \mathrm{N})\end{array}$ & Percentage & $\begin{array}{l}\text { Frequencies } \\
(\mathrm{n} / \mathrm{N})\end{array}$ & Percentage & \\
\hline \multicolumn{6}{|l|}{ Mother's follow up for PMTCT ${ }^{* \star}$} \\
\hline - Yes & $18 / 118$ & 15 & $15 / 211$ & 7 & $<0.001$ \\
\hline - No & $100 / 118$ & 85 & $178 / 211$ & 84 & \\
\hline - Unknown & & & $18 / 211$ & 9 & \\
\hline \multicolumn{6}{|l|}{ CDC clinical stage $e^{* * *}$} \\
\hline - $\mathrm{A}$ & $53 / 118$ & 44.9 & - & - & \\
\hline - $\mathrm{B}$ & $20 / 118$ & 16.9 & - & - & \\
\hline - $\mathrm{C}$ & $11 / 118$ & 9.3 & - & - & \\
\hline - $\mathrm{N}$ & $18 / 118$ & 15.3 & - & - & \\
\hline - Unspecified & $16 / 118$ & 13.6 & - & - & \\
\hline \multicolumn{6}{|l|}{ Nutritional status } \\
\hline - Good & $29 / 118$ & 24.6 & $26 / 211$ & 12.3 & $<0.001$ \\
\hline - Severe acute malnutrition & $22 / 118$ & 18.6 & $106 / 211$ & 50.2 & \\
\hline - Moderate acute malnutrition & $12 / 118$ & 10.2 & $20 / 211$ & 9.5 & \\
\hline - Non-determined & $55 / 118$ & 46.6 & $59 / 211$ & 28 & \\
\hline \multicolumn{6}{|l|}{ CD4 count at the start of treatment } \\
\hline - $\leq 200$ & $6 / 40$ & 15 & $21 / 74$ & 28.4 & 0.5 \\
\hline - $\quad] 200 ; 350]$ & $6 / 40$ & 15 & $8 / 74$ & 10.8 & \\
\hline - $] 350 ; 500]$ & $4 / 40$ & 10 & $4 / 74$ & 5.4 & \\
\hline - $>500$ & $24 / 40$ & 60 & $41 / 74$ & 55.4 & \\
\hline \multicolumn{6}{|l|}{ Associated pathologies } \\
\hline - Malnutrition & $34 / 61$ & 55.7 & $126 / 157$ & 80.2 & 0.001 \\
\hline - Tuberculosis & $7 / 61$ & 11.5 & $11 / 157$ & 7 & \\
\hline
\end{tabular}




\section{Continued}

$\begin{array}{lcccc}\text { - Pneumonia } & 4 / 61 & 6.55 & 4 / 157 & 2.5 \\ \text { - Rhinobronchitis } & 4 / 61 & 6.55 & 3 / 157 & 1.9 \\ \text { - Anemia } & 3 / 61 & 4.9 & 0 / 157 & 0 \\ \text { - Oral candidiasis } & 2 / 61 & 3.3 & 2 / 157 & 11.3 \\ \text { - Others } & 7 / 6 * & 11.5 & 11 / 157 & 7\end{array}$

${ }^{\star}$ Child living with HIV; ${ }^{* *}$ Prevention of mother-to-child transmission of HIV; ${ }^{* *}$ Centers for disease control and prevention; ${ }^{* * *}$ Herpes zoster (1), Viral hepatitis B (1), angina (1), dermatosis (1), poly lymphadenopathy (1), purulent otorrhea (1), acute gastroenteritis (1).

Table 3. Therapeutic characteristics of HIV/AIDS with non-suppressed viraemia.

\begin{tabular}{|c|c|c|c|c|c|}
\hline \multirow[b]{2}{*}{ Variables } & \multicolumn{2}{|c|}{ unsuppressed viremia } & \multicolumn{2}{|c|}{ suppressed viremia } & \multirow[b]{2}{*}{$\mathrm{p}$ Value } \\
\hline & $\begin{array}{l}\text { Frequencies } \\
\qquad(\mathrm{n} / \mathrm{N})\end{array}$ & Percentage & $\begin{array}{l}\text { Frequencies } \\
\qquad(\mathrm{n} / \mathrm{N})\end{array}$ & Percentage & \\
\hline \multicolumn{6}{|l|}{ Therapeutic regimen ${ }^{*}$} \\
\hline - $\mathrm{ABC}-3 \mathrm{TC}-\mathrm{EFV}$ & $46 / 118$ & 39 & $121 / 211$ & 57.3 & 0.018 \\
\hline - $\mathrm{ABC}-3 \mathrm{TC}-\mathrm{LPV} / \mathrm{r}$ & $30 / 118$ & 25.4 & $36 / 211$ & 17.1 & \\
\hline - AZT-3TC-NVP & $15 / 118$ & 12.7 & $11 / 211$ & 5.2 & \\
\hline - TDF-3TC-EFV & $11 / 118$ & 9.3 & $22 / 211$ & 10.4 & \\
\hline - AZT-3TC-EFV & $5 / 118$ & 4.2 & $10 / 211$ & 4.7 & \\
\hline - $\mathrm{ABC}-3 \mathrm{TC}-\mathrm{NVP}$ & $4 / 118$ & 3.4 & $5 / 211$ & 2.3 & \\
\hline - $\mathrm{ABC}-3 \mathrm{TC}-\mathrm{AZT}$ & $2 / 118$ & 1.7 & $1 / 211$ & 0.5 & \\
\hline - ABC-3TC-TDF & & & $1 / 211$ & 0.5 & \\
\hline - AZT-3TC-LPV & & & $2 / 211$ & 1 & \\
\hline - Not mentioned & $5 / 118$ & 4.2 & $2 / 211$ & 1 & \\
\hline \multicolumn{6}{|l|}{ Cotrimoxazole } \\
\hline - Start & $69 / 118$ & 58.5 & $123 / 211$ & 58.3 & 0.34 \\
\hline - Ongoing & $9 / 118$ & 7.6 & $18 / 211$ & 8.5 & \\
\hline - No & $22 / 118$ & 18.6 & $26 / 211$ & 12.3 & \\
\hline - Not mentioned & $18 / 118$ & 15.3 & $44 / 211$ & 20.9 & \\
\hline \multicolumn{6}{|l|}{ Compliance to $\mathrm{ART}^{* *}$} \\
\hline - Yes & $64 / 118$ & 43 & $185 / 211$ & 87.7 & $<0.0001$ \\
\hline - No & $51 / 118$ & 54 & $16 / 211$ & 7.6 & \\
\hline - Not mentioned & $3 / 118$ & 3 & $10 / 211$ & 4.7 & \\
\hline \multicolumn{6}{|l|}{ Reason for non-compliance } \\
\hline - Oversight & $6 / 118$ & 5.1 & - & - & \\
\hline $\begin{array}{l}\text { - Non-compliance with } \\
\text { prescriptions }\end{array}$ & $5 / 118$ & 4.2 & - & - & \\
\hline
\end{tabular}




\section{Continued}

\begin{tabular}{|c|c|c|c|c|}
\hline - Interruption of treatment & $3 / 118$ & 2.5 & - & - \\
\hline - Skipping medication & $3 / 118$ & 2.5 & - & - \\
\hline - Bad adherence & $2 / 118$ & 1.7 & - & - \\
\hline - Negligence & $1 / 118$ & 0.9 & - & - \\
\hline - Not mentioned & $98 / 118$ & 83.1 & - & - \\
\hline
\end{tabular}

${ }^{\star} \mathrm{ABC}=$ abacavir; 3TC = lamivudine; EFV = efavirenz; NVP = nevirapine; TDF $=$ tenofovir; $\mathrm{AZT}=$ zidovudine; $\mathrm{LPV} / \mathrm{r}=$ lopinavir boosted with ritonavir; ${ }^{\star *}$ antiretroviral therapy.

Table 4. Factors associated with unsuppressed viral load in children living with HIV receiving antiretroviral therapy in the Gbêkê region.

\begin{tabular}{|c|c|c|c|c|}
\hline \multirow{2}{*}{ Variables } & \multicolumn{2}{|c|}{ Viral load } & \multirow{2}{*}{$\begin{array}{l}\text { Odds ratio } \\
\text { [IC95\%] }\end{array}$} & \multirow{2}{*}{ p Value } \\
\hline & Suppressed & Unsuppressed & & \\
\hline \multicolumn{5}{|c|}{ Nutritional status } \\
\hline Good & 26 & 29 & \multirow{2}{*}{$0.24[0.13-0.46]$} & \multirow{2}{*}{$<0.001$} \\
\hline Malnutrition & 126 & 34 & & \\
\hline \multicolumn{5}{|l|}{ Compliance } \\
\hline Yes & 185 & 64 & \multirow{2}{*}{$9.2[5.17-18.68]$} & \multirow{2}{*}{$<0.001$} \\
\hline No & 16 & 51 & & \\
\hline \multicolumn{5}{|c|}{ Mother education level } \\
\hline Schooled & 60 & 20 & \multirow{2}{*}{$2.2[1.19-4.06]$} & \multirow{2}{*}{0.011} \\
\hline Unschooled & 75 & 55 & & \\
\hline \multicolumn{5}{|l|}{ PMTCT $^{*}$} \\
\hline Yes & 15 & 18 & \multirow{2}{*}{$0.46[0.22-0.93]$} & \multirow{2}{*}{0.03} \\
\hline No & 178 & 100 & & \\
\hline
\end{tabular}

${ }^{\star}$ Prevention of mother-to-child transmission of HIV.

\section{Discussion}

This retrospective descriptive and analytical work carried out in 28 centers for the management of HIV infection in children in the Gbêkê region aims to research the factors associated with unsuppressed viral load of children aged 0 to 15 years old living with HIV and on antiretroviral therapy. The study shows that the prevalence of unsuppressed viral load is high in children on antiretroviral therapy in the Gbêkê region and is accompanied by various pathologies. The factors associated with this unsuppressed viral load are nutritional, therapeutic and maternal. However, the results must be qualified. Indeed, the study only concerned children whose follow-up was evaluated after just one year of treatment, and who had achieved a viral load during this first year of treatment. In addition, regular updates of national guidelines for the care of PLWHIV could constitute a selection bias. The retrospective nature of the study with its corol- 
lary of missing information constitutes a bias that could underestimate or overestimate the results of the study. Despite the methodological limitation, the results of the study raise the following points of discussion in terms of prevalence, socio-demographic, diagnostic, therapeutic and evolutionary characteristics.

- Concerning the prevalence and socio-demographic characteristics of the mother-child couple

The prevalence of unsuppressed viral load in children receiving antiretroviral therapy in the Gbêkê region is high (36\%). Asse et al. [7] in 2019 in Bouaké (Ivory Coast) reported a prevalence of 38.3\%. Cissé et al. [3] in Senegal in 2015 and Penda et al. [4] in 2013 in Cameroon respectively found a prevalence of 64\% and $17.6 \%$. This variability could be explained on the one hand by methodological differences and on the other hand by the care guidelines for PLWHIV varying from one country to another. However, all these studies have the merit of demonstrating that the absence of viral suppression in the management of HIV/AIDS constitutes a major public health problem in sub-Saharan Africa. In this work, the child living with HIV (HIV/AIDS) with unsuppressed viremia is in the majority of cases male ( $\operatorname{sex}$ ratio $=1.2$ ). This result is comparable to that found by Haile et al. [9] in 2019 in Ethiopia with a sex ratio of 1.32. On the other hand, other authors have reported a predominance of women. Indeed, Almeida et al. [10] in 2013 in Benin and Mossoro-Kpinde et al. [11] in 2017 in the Central African Republic reported a sex ratio of 0.9 and 0.86 respectively. Asse et al. [7] in 2019 in Bouaké (Ivory Coast) did not report a difference in sex. In $60.7 \%$ of cases, the children are under 5 years old at the time of diagnosis. This late diagnosis of HIV infection in children points to an inadequate strategy to prevent mother-to-child transmission of HIV (PMTCT). This hinders the early initiation of ART and certainly explains why in the study the initiation of ART in children was carried out in $66.7 \%$ of cases beyond the age of 24 months, with an average age of 65,8 months. In the PMTCT unit of the pediatric department of the Bouaké University Hospital, Asse et al. [7] reported in 2019, mean age of 57.9 months at the start of ART. Oumar et al. [12] in Ségou, Mali in 2016, also reported late initiation of antiretroviral therapy with a mean age at initiation of treatment of 5 years.

The initiation of treatment at a late age in children living with HIV increases the risk of developing opportunistic diseases in children which are functional and life-threatening. WHO therefore recommends stepping up strategies for the detection and early treatment of children infected with HIV [13]. In the present study, approximately 2 out of 3 children lived in urban areas. This could be explained by the decentralization of care for PLWHIV in the region of Gbêkê and by a high concentration of pediatric HIV infection care centers (19/28) were in the only town of Bouake. With regard to the mothers of these children, it emerges from this work that $45.8 \%$ of the mothers are illiterate. This low level of education could explain the high proportion of housewives (31.4\%) and small traders (36.4\%) in the study. In Asse et al.'s study in 2019 [7], the proportion of 
housewives represented $71.3 \%$. Dainguy et al. [14] reported $11.1 \%$ of uneducated mothers at Cocody University Hospital in Abidjan in 2014. This finding thus raises the problem of women's schooling with the low socio-economic level as a corollary. According to UNESCO, the literacy rate for women does not exceed $50 \%$ in more than 12 countries in sub-Saharan Africa [15]. The low level of maternal education is a factor associated with the unsuppressed viral load in children living with HIV ( $\mathrm{p}=0.011$ ) in the study. The low level of education of the mother represents, in terms of health vulnerability, danger and constitutes an obstacle to the implementation of PMTCT as well as to the achievement of good compliance to treatment [9].

\section{- At the diagnostic level}

The study found that $85 \%$ of mothers did not receive PMTCT follow-up. This result is similar to that of Cissé et al. [3] who had found $70 \%$ of mothers did not followed-up within the framework of PMTCT. Haile et al. [9] made the same observation with $93.4 \%$ of mothers. The insufficient follow-up of mothers within the framework of PMTCT negatively impacts that of their child. This observation is made in the study by Asse et al. [7] which reported 90.5\% of children not having received antiretroviral prophylaxis for PMTCT. Kouakou et al. [16] found a loss of follow-up at 12 months of $100 \%$ in the setting of PMTCT. This low rate of PMTCT achievement is a factor associated with unsuppressed viral load ( $\mathrm{p}=0.03$ ). It could be explained by the non-respect of the appointments by the mothers, the refusal of the follow-up by the parents, the fear of stigmatization and the denial of the disease in our African socio-cultural context. The HIV 1 serotype is found in all children with non-suppressed viremia. Almeida et al. [10] in Benin in 2013 reported 100\% of HIV 1 cases. Asse et al. [7] in 2019 at the Bouaké University Hospital had found HIV 1 in $92.8 \%$ and HIV 2 in $7.2 \%$ of cases. The same observation was made by Cisse et al. [3] in Senegal in 2015 with HIV 1 in $96.7 \%$ and HIV 2 in $2.2 \%$ of cases. The high proportion of HIV 1 in these studies could be explained by the fact that among the 3 types of HIV, HIV 1 is the most common serotype in sub-Saharan Africa [17]. In the study, the child was in good nutritional status in about a quarter of cases and was malnourished in $28.8 \%$. This is severe malnutrition in $18.6 \%$ and moderate in $10.2 \%$ of cases. For Cissé et al. [3] in Senegal in 2015, children had good nutritional status in $59 \%$ and were malnourished in $27 \%$ of cases. In 2011, Jesson et al. [18] reported that $42 \%$ of HIV-positive children suffered from malnutrition in West and Central Africa. A higher frequency (60.2\%) was found by Mwadianvita et al. [19] in 2014 in Congo. These results confirm the close link between malnutrition and HIV/AIDS infection. Malnutrition is a factor of poor prognosis in children living with HIV. It worsens the disease, increases morbidity and decreases the chances of survival of the immunocompromised child. Thus in this work, poor nutritional status is identified as a factor associated with unsuppressed viral load ( $\mathrm{p}<0.001)$. Malnutrition (55.7\%), tuberculosis $(11.5 \%)$, pneumonia $(6.55 \%)$ and nasopharyngitis $(6.55 \%)$ are the main pathologies encountered in children infected with HIV with unsuppressed viremia. Dicko et al. [20] in Mali in 2013 
and Diarrassouba et al. [21] in Côte d'Ivoire in 2010 found the same associated pathologies but in different proportions. This high proportion of associated pathologies is the consequence of immunosuppression due to the drop in the TCD4 lymphocyte level, which is inversely proportional to the viral load. This exposes the child to all kinds of pathologies and opportunistic infections. In the study, $44.9 \%$ of children are at stage A and $9.3 \%$ at stage C of the CDC classification. These results are different from those of Asse et al. [7] in 2019 in Bouaké in Côte d'Ivoire, which found $46 \%$ of children at stage C. Ouedraogo et al. [22] in Burkina Faso in 2015 found $43.5 \%$ of children at stage III and IV of the WHO classification. This difference could be explained by a methodological bias, in fact, this work is multicentric, while the studies by Asse et al. [7] and Ouedraogo et al. [22] were monocentric and hospital-based, which may justify the large proportion of children with advanced disease. In the study, $60 \%$ of the children had a CD4 count $>500$ cells $/ \mathrm{mm}^{3}$. This result is similar to that of Haile et al. [9] in Ethiopia 2019 who found $75.8 \%$ of children with a CD4 count $>500$ cells $/ \mathrm{mm}^{3}$.

\section{- At the therapeutic and evolutionary level}

In the study all the children with high viremia were on triple therapy; it is the combination of $2 \mathrm{NRTI}+1 \mathrm{NNRTI}$ in $68.6 \%$, $2 \mathrm{NRTI}+$ boosted PI in $25.4 \%$ and 3NRTI in $1.7 \%$ of cases. Asse et al. [7] in Bouaké in 2019 reported therapeutic regimens combining 2 NRTI +1 NNRTI in $90.5 \%$, 3NRTI in $5.9 \%$ and 2 NRTI + boosted PI in 3.6\% of cases. These treatment protocols comply with the various national guidelines for the management of HIV/AIDS. Still, on the therapeutic level, the study shows that cotrimoxazole prophylaxis is initiated at the start of treatment in $69 \%$ of cases and in $22 \%$ of cases is not performed. This low rate of initiation of Cotrimoxazole at the start of treatment could be explained by the clinical and/or biological status of certain patients, which contraindicates its initiation. In addition, some patients may have experienced side effects from the drug, leading the health worker to stop this prophylaxis. The study found that only $54 \%$ of children adhere to ART. The same observation was made by Penda et al. [4] in 2013 in Cameroon, which reported 41\% compliance among children with treatment failure. The low rate of children observed in this work could be explained by the non-compliance with the times of intake or the dosages by the parents. In addition, the side effects of ARTs could act as an obstacle on good compliance. Another cause for poor compliance is denial of the disease by parents or by the child for fear of stigma. This poor compliance results in the development of resistance to ARTs and non-suppression of viral load during the course of this treatment. In fact, in this work, poor compliance is a factor associated with unsuppressed viral $(\mathrm{p}<0.001)$. The child with unsuppressed viremia is still in the active queue in $94.8 \%$ of cases, lost to follow-up in $1.7 \%$ and died in $0.9 \%$ of cases. This high rate of retention of children in care and the low rate of loss of follow-up and death reflect on the one hand the effectiveness of the strategies put in place by all the actors involved in the fight against HIV/AIDS, and on the other hand, the effectiveness of ART. 


\section{Conclusion}

Non-suppression of viral load in HIV-positive children is common in the Gbêkê region. It most often concerns the boy in whom the diagnosis and initiation of ART were late. The mother of this child is mostly illiterate and has not been followed for PMTCT. This non-suppression viral load is accompanied by various pathologies affecting the prognosis of the child. The factors associated with this unsuppressed viremia are poor nutritional status at the start of treatment, poor compliance to treatment, low level of mother's education and lack of maternal follow-up for PMTCT. Thus, the fight against illiteracy and poverty, reinforcement of screening, early initiation of ART, PMTCT strategy, active search for those lost to follow-up and accentuation of therapeutic education strategies would make it possible to improve the prognosis of children infected with HIV.

\section{Authors' Contributions}

All authors contributed intellectually to the preparation and revision of the manuscript prior to its submission.

\section{Acknowledgements}

NGO IRAA, Health Regional Directorate of Gbêkê, Responsible for all health centers involved in pediatric HIV care in the region of Gbêkê.

\section{Conflicts of Interest}

The authors declare no conflicts of interest regarding the publication of this paper.

\section{References}

[1] UNAIDS (The Joint United Nations Programme on HIV/AIDS) (2021) Latest Global Statistics 2020.

https://www.unaids.org/sites/default/files/media_asset/UNAIDS_FactSheet_fr.pdf

[2] UNAIDS (The Joint United Nations Programme on HIV/AIDS) (2016) Consolidated Guidelines on the Use of Antiretroviral Drugs for Treating and Preventing HIV Infection: Recommendations for a Public Health Approach. 2nd Edition, The Joint United Nations Programme on HIV/AIDS, Geneva, 129 p.

[3] Cissé, A.M., Laborde-Balen, G., Kébé-Fall, K., Aboubacry Dramé, A., Diop, H., Diop, K., et al. (2019) High Level of Treatment Failure and Drug Resistance to First-Line Antiretroviral Therapies among HIV-Infected Children Receiving Decentralized care in Senegal. BMC Pediatrics, 19, Article No. 47.

https://doi.org/10.1186/s12887-019-1420-Z

[4] Penda, C.I., Bebey, F.S., Mangamba, D.K., Moukoko, E.C.E., Ngwa, V., Makouet, N., et al. (2013) Treatment Failures among HIV-Infected Children under Routine Follow-Up in a Resource-Limited Setting in Cameroon. Pan African Medical Journal, 15, Article No. 80. https://doi.org/10.11604/pamj.2013.15.80.2754

[5] Zohoun, L., Alihonou, F., Bagnan, L., Ahouassa, J. and d'Almeida, M. (2019) Factors Associated with Treatment Failure in Children on Antiretroviral Drugs Followed at the Centre National Hospitalier Universitaire de Cotonou. African Journal 
of Pediatrics and Medical Genetics, 8, 40-43.

[6] UNAIDS (The Joint United Nations Programme on HIV/AIDS) (2020) Country Factsheets: Côte d'Ivoire 2020.

https://www.unaids.org/fr/regionscountries/countries/ctedivoire

[7] Asse, K.V., Yao, K.C., Azagoh-Kouadio, R., Yeboua, K.R., Ehouman, M.A., Aka-Tanoh, K.A., et al. (2019) Profile of Children Living with HIV Followed up from 2005 to 2016 in the Prevention of Mother to Child Transmission (PMCT) HIV Unit at the University Teaching Hospital (UTH) of Bouake Côte d'Ivoire. International Journal of Pediatrics Neonatal Health, 3, 1-6.

[8] Kouassi, K., Sreu, E. and Koua, A.M. (2019) Prayer Camps: Health Safety Valve in Desert of Psychiatric Care in the Health Region of Gbêkê (Center of Côte d'Ivoire). Revue Ivoirienne de Géographie des Savanes, No. Special Issue, 306-326. https://www.riges-uao.net/volumes/numero-special/fichiers/art17.pdf

[9] Haile, G.S. and Berha, A.B. (2019) Predictors of Treatment Failure, Time to Switch and Reasons for Switching to Second Line Antiretroviral Therapy in HIV Infected Children Receiving First Line Anti-Retroviral Therapy at a Tertiary Care Hospital in Ethiopia. BMC Pediatrics, 19, Article No. 37.

https://doi.org/10.1186/s12887-019-1402-1

[10] Almeida, M., Sagbo, G., Lalya, F., Alao, M.J., Almeida, C., Agossou, J., et al. (2013) Profil of Children Infected by HIV, Followed at the National Hospital Center of Cotonou. Mali Medical, 1, 25-39.

[11] Mossoro-Kpinde, C.D., Gody, J.C., Mboumba Bouassa, R.S., Mbitikon, O., Jenabian, M.A., Robin, L., et al. (2017) High Levels of Virological Failure with Major Genotypic Resistance Mutations in HIV-1-Infected Children after 5 Years of Care According to WHO-Recommended 1st-Line and 2nd-Line Antiretroviral Regimens in the Central African Republic. Medicine, 96, Article No. e6282.

https://doi.org/10.1097/MD.0000000000006282

[12] Oumar, A.A., Katile, D., Maiga, B., Touré, A., Drabo, M., Togo, B., et al. (2016) Evaluation of Antiretroviral Adherence in Children in Segou, Mali. Anthropologie, 35, 83-89.

[13] World Health Organization (2017) Unified Guidelines on Monitoring HIV-Infected Patients and Case Surveillance Using a Person-Centered Approach. World Health Organization, Geneva.

https://apps.who.int/iris/bitstream/handle/10665/260135/9789242512632-fre.pdf?se quence $=1$ \&isAllowed $=\mathrm{y}$

[14] Dainguy, M.E., Folquet, A.M., Kouadio, E., et al. (2014) Experience of Mothers Who Received Prevention of Mother-to-Child Transmission PMTCT in a referral center in Abidjan. Medecine d Afrique Noire, 61, 64-70.

[15] UNESCO (The United Nations Educational, Scientific and Cultural Organization) (2018) Education of Girls and Women-Statistics. https://www.unesco.org

[16] Kouakou, K.P., Doumbia, Y., Djanhan, L.E., Menin, M.M., M’bro, C. and Djanhan, Y. (2016) Séroprévalence, Management and Fetal Prognosis of HIV Infection during Pregnancy at CHU Bouaké. Revue International des Sciences Médicales, 18, 280-285.

[17] Bissagnéné, E., Dariosecq, J.M., Drabo, J., Inwoley, A., Sow, P.S., Tabouret, A.M., et al. (2005) Memento on HIV/AIDS treatment in Africa. 2nd Edition, Doin, Paris.

[18] Jesson, J., Masson, D., Adonon, A., Tran, C., Habarugira, Zio, R., Nicimpaye, L., desmonde, S., Serurakuba, G., Kwayep, R., et al. (2015) Prevalence of Malnutrition among HIV-Infected Children in Central and West-African HIV-Care Programmes 
Supported by the Growing Up Programme in 2011: A Cross-Sectional Study. BMC Infectious Diseases, 15, Article No. 216. https://doi.org/10.1186/s12879-015-0952-6

[19] Mwandianvita, K.C., Kanyenze, N.F., Wembonyama, W.C.A., Mutomb, M.F., Mupoya, K.A., Nkoy, M.T.A. and Mwenze, K.P. (2014) Nutritional Status of Children Aged 6 to 59 Months Infected with HIV but Not Treated with ARVs in Lumbumbashi. Pan African Medical Journal, 19, Article No. 7.

[20] Dicko, T.F., Koné, A., Sylla, M., Diakité, A., Konaté, D., Konaté, Y., et al. (2013) Causes of Hospitalization of HIV-Infected Children in the Pediatric Ward of the Gabriel Touré University Hospital in Bamako. Mali Medical, 28, 37-43.

[21] Diarrasouba, G., Niamien, E., Kaudhjis, Adonis-Koffi, L. and Koutou, E. (2010) Causes of Hospitalization of HIV-Infected Children in Côte d'Ivoire. Archives of Pediatrics, 17, 168. https://doi.org/10.1016/S0929-693X(10)70866-6

[22] Ouedraogo, S., Zoungrana, J., Sondo, K.A., Barro, M., Kyélem, C.G. and Konate, I. (2015) Study of Factors Associated to Therapeutic Failure of Children Infected by HIV1 under Treatment in Sanou Souro Unviersity Hospital of Bobo Dioulasso (2007-2013). Mali Medical, 30, 26-31. 